\title{
O mercado e o pescado: uma primeira atualização dos circuitos econômicos e das cadeias produtivas do peixe em Santa Maria - RS
}

\author{
The market and the fish: a first upgrade of economic circuits \\ and of productive chains of fish in Santa Maria - RS
}

\author{
Eduardo Schiavone Cardoso ${ }^{1}$, Carmen Luyara Canabarro Leal ${ }^{2}$, Jéssica Medeiros Costa ${ }^{3}$ \\ 1,2,3 Universidade Federal de Santa Maria - Santa Maria - RS - Brasil
}

\begin{abstract}
Resumo
O objetivo do trabalho consiste em apresentar elementos para a análise das cadeias de produção, circulação e consumo do pescado no município de Santa Maria. Objetiva também analisar os espaços geoeconômicos e os circuitos espaciais envolvidos em tais cadeias produtivas. O estudo atualiza as informações acerca do comércio de pescado em Santa Maria, levantadas pela primeira vez em 2005, permitindo identificar as mudanças na estrutura local do varejo e estimar a dinâmica da comercialização de pescado na cidade. Analisa a dinâmica de um circuito produtivo de pescado local, representado pela piscicultura de água doce, cujo incremento tem se realizado de forma gradual, mas que apresenta elementos novos e importantes do ponto de vista da economia do pescado na cidade. Identifica também as etapas das cadeias produtivas e dos circuitos espaciais de produção do pescado de âmbito global, que se realizam e estão presentes na cidade.
\end{abstract}

Palavras-chave: mercado; pescado; cadeias produtivas; Santa Maria

\begin{abstract}
The aim of this paper is to present elements to analyze the productive chains, circulation and consumption of fish in Santa Maria town. It aims also to analyze the geo-economics spaces and the spatial circuits engaged in such productive chains. The study updates the information upon the fish trade in Santa Maria, first researched in 2005, allowing to identify the changes in local structure of retail business and to estimate the commercialization dynamic of fish in the town. It analysis the dynamic of a productive circuit of local fish, represented by the freshwater fish farming, whose increment has been carried out in a gradual way, but that presents new and important elements considering the fish economy in the town. It identifies also the steps of the productive chains and of the spatial circuits of fish production in a global view, that are carried out and present in the town.
\end{abstract}

Keywords: market; fish; productive chains; Santa Maria 


\section{Introdução}

O presente estudo abrange dois eixos centrais. O primeiro atualiza as informações adquiridas em 2005, acerca do comércio de pescado em Santa Maria - RS, Brasil. Na ocasião, através de um projeto FIPE - UFSM, foram identificados alguns dos circuitos produtivos que desembocam no consumo do pescado na cidade, bem como a estrutura do comércio varejista local. Através de um novo apoio e com novos participantes, no ano de 2010 foi possível realizar uma atualização das informações, permitindo analisar a dinâmica deste segmento do processo produtivo e parte da cadeia econômica do pescado na cidade, em um intervalo de cinco anos a partir do final do primeiro levantamento.

O segundo eixo de estudo consiste na análise de um circuito produtivo de pescado, com forte componente local, representado pela piscicultura de água doce, cujo incremento tem se realizado de forma gradual, mas que apresenta elementos novos e importantes do ponto de vista da economia do pescado na cidade. Nesse sentido o objetivo é apontar o papel de tal segmento produtivo na oferta do pescado em Santa Maria.

Ao considerar o conceito de cadeias produtivas para o estudo do pescado consumido na cidade, são identificadas as etapas e os agentes produtivos envolvidos em tais cadeias, que apresentam uma primeira diferenciação: o pescado oriundo da pesca extrativa e o pescado cultivado. Para uma conceituação inicial, as cadeias produtivas podem ser entendidas como o resultado da divisão técnica e social do trabalho e a interrelação entre agentes econômicos que atuam nas distintas etapas do processo produtivo (DALL'ACQUA, 2003).

No caso do pescado, os agentes econômicos diferenciam-se entre pescadores, empresas de beneficiamento, aquicultores, distribuidores, mercados varejistas, consumidores, entre outros, cuja articulação se realiza ao longo do processo produtivo, transformando peixe em mercadoria, estabelecendo trocas financeiras e valorando as ações empreendidas. Tais agentes atuam desde a escala local, até escalas mais amplas compreendendo o globo.

As cadeias produtivas são resultados da crescente divisão do trabalho e da maior interdependência entre os agentes econômicos. São caracterizadas por três elementos: a) uma sucessão de operações de transformação dissociáveis, capazes de serem separadas e ligadas entre si por um encadeamento técnico; b) um conjunto de relações comerciais e financeiras aliado a um fluxo de troca, situado de montante a jusante, entre fornecedores e clientes; e c) um conjunto de ações econômicas que preside a valoração dos meios de produção e assegura a articulação das operações (PAULILLO, 2000).

Para Santos (1997), os "circuitos produtivos se dão, no espaço, de forma desagregada, embora não desarticulada". O autor também conceitua os circuitos espaciais de produção como "as diversas etapas pelas quais passaria um produto, desde o começo da produção até chegar ao consumo final". Sendo assim, circuitos econômicos são constituídos pelos fluxos e pelas unidades econômicas, é a espacialização da produção. E cadeias produtivas são os processos de produção até obter o produto final.

No caso deste estudo o produto final da cadeia produtiva é o pescado, que envolve agentes econômicos como os pescadores, empresas de beneficiamento, aquicultores, distribuidores, mercados varejistas, consumidores, entre outros, cuja articulação se realiza ao longo do processo produtivo, transformando peixe em mercadoria, estabelecendo trocas financeiras e valorando as ações empreendidas

\section{Material e métodos}

O trabalho realizado contou, primeiramente, com a sistematização dos dados secundários presentes nas estatísticas globais compiladas pela FAO (Organização das Nações Unidas para a Agricultura e Alimentação) e divulgados a cada dois anos no relatório intitulado "O Estado Mundial da Pesca e da Aquicultura", apelidado de SOFIA (FAO, 2009). Para o caso brasileiro, os dados foram obtidos nos relatórios estatísticos do Ministério da Pesca e Aquicultura brasileiro que, a partir de 2009, substituiu o IBAMA na divulgação dos boletins oficiais de produção pesqueira e aquícola (MPA, 2012). Foram consultados também os resultados das Pesquisas de Orçamento Familiar - POF's, realizadas pelo IBGE (IBGE, 2011). Com tais informações aproximamos das ordens de grandeza dos setores pesqueiro e aquícola brasileiros, em termos de produção e consumo, bem como sua relação com os demais países.

Com relação ao cálculo do consumo aparente do pescado no Brasil, é importante destacar que o Ministério da Pesca e da Aquicultura trabalha com os dados convertidos, tendo por base o peso bruto e o peso líquido do pescado importado e exportado. Com tal metodologia, adotada recentemente, os números crescem para a faixa dos $9 \mathrm{~kg} / \mathrm{hab}$./ano. Optamos por fazer o cálculo sem a referida conversão, pois assim acompanhamos uma série que vem sendo calculada desde a década de 1970 (SORJ, 1986).

Para Santa Maria, os dados de produção de pescado foram obtidos através do contato com os 
produtores, dirigentes da COOPISCENTRO (Cooperativa de Piscicultores da Região Centro). A Feira do Peixe Vivo, realizada durante a Semana Santa de 2012, em Santa Maria, foi visitada, observando aspectos da comercialização e limpeza do pescado, as espécies vendidas e seus preços. Com relação ao mercado de pescado na cidade, foram realizados levantamentos da rede de comércio varejista de alimentos, identificando as pequenas redes de mercados, estabelecimentos dos grandes grupos internacionais e peixarias especializadas.

Em parte desses estabelecimentos, foram obtidas informações a respeito da origem do produto comercializado na cidade, quantidade aproximada de venda mensal, preferências dos clientes, modo como o pescado é apresentado ao consumidor, entre outras questões levantadas a partir de entrevistas com gerentes e responsáveis pelo setor. No entanto, não obteve-se resposta nas indagações apresentadas para $25 \%$ dos principais conjuntos de empresas identificadas.

\section{Resultados e discussão}

O setor varejista de pescado em Santa Maria, pesquisado em 2005, contava com três redes associadas de mercados de pequeno e médio porte - Redes Super, Central-Mais e Unimercados; dois hipermercados e mais um mercado menor pertencentes a uma corporação internacional - Walmart e uma rede local, com um hipermercado e duas outras lojas - Dois Irmãos. Além dos mercados descritos, três peixarias e outros mercados não associados às redes também comercializavam pescado (CARDOSO et al, 2006).

No intervalo de seis anos ocorreram transformações nessa composição. Atualmente uma das três redes de pequenos e médios mercados segue em evidência - Rede Super, ao passo que as duas demais têm atuação limitada; além do Walmart, a cidade conta também com a presença do Carrefour, ambos com suas lojas atacadistas; surge uma nova empresa de porte estadual - Rede Vivo; as passo que houve uma mudança da marca dos Dois Irmãos para a marca Peruzzo, com a abertura de uma nova loja. Das três peixarias existentes em 2005, duas foram fechadas e apenas uma permanece em atividade. A ela, soma-se uma nova peixaria aberta há dois anos.

O que podemos afirmar é que ocorreram algumas alterações na estrutura de comercialização do pescado na cidade, sintetizadas na Tabela 1, com a internalização na cidade da disputa global entre duas corporações varejistas transnacionais, uma reestruturação das redes locais de pequenos e médios mercados e a presença de empresas médias atuando como redes.
Tabela 1: Número e tipo de empresas varejistas

\begin{tabular}{|c|c|c|}
\hline Varejo/Ano & 2005 & 2011 \\
\hline $\begin{array}{c}\text { Redes associadas de mercados de } \\
\text { pequeno e médio porte }\end{array}$ & 3 & 2 \\
\hline Corporações internacionais & 1 & 2 \\
\hline Empresas locais & 1 & 2 \\
\hline Peixarias & 3 & 2 \\
\hline
\end{tabular}

Fonte: CARDOSO, 2006 e trabalho de campo.

De acordo com a pesquisa, a grande maioria do pescado comercializado em Santa Maria vem de outros lugares, tais como: a cidade de Rio Grande - RS, o estado de Santa Catarina, região nordeste do país e países do Mercosul. Esses pescados são comercializados nas redes de mercados, hipermercados e peixarias da cidade. Duas áreas produtoras e respectivos produtos, entretanto, passam a figurar como fornecedores de pescado a partir de anos mais recentes: a China, com a merluza chamada polaca, e o Vietnan, com o panga.

No caso deste último, recentemente disponível no mercado brasileiro, dos estabelecimentos de varejo de pescado visitados, apenas dois não comercializam o produto, sendo que nos demais o produto é bem aceito. Sua introdução no mercado santa-mariense também é recente, constitui-se em um produto de praticidade para o consumo, sem pele e com preço acessível à população. Cabe ressaltar que há uma polêmica frente a sua importação, noticiada em veículos da imprensa.

Contrapondo-se a este exemplo de circuitos produtivos de escala global, Santa Maria tem um significativo comércio de pescado produzido localmente durante a Feira do Peixe Vivo, que ocorre durante as Semanas Santas, e que já realizou quase duas dezenas de edições. A feira é o ápice da venda do pescado cultivado no município, dividindo-se em alguns pontos na cidade, com pontos de comercialização na Gare, na Tancredo Neves, no bairro Jucelino Kubitschek, em Camobi e na Avenida Ângelo Bolson. Dessa forma, constata-se a coexistência de cadeias e circuitos produtivos de escalas variadas - local, regional, nacional e global, competindo pelos consumidores no comércio do pescado.

O consumo de pescado foi estimado pela FAO como abastecido por uma disponibilidade de 16 quilos de pescado por habitante do globo. O mesmo órgão recomenda o consumo de cerca de 12 quilos de pescado/habitante/ano. No caso brasileiro, são 
Tabela 2: Consumo aparente do pescado no Brasil

\begin{tabular}{|c|c|c|c|c|c|c|}
\hline Ano & Produção (t) & $\begin{array}{c}\text { Importações } \\
(\mathbf{t})\end{array}$ & $\begin{array}{c}\text { Exportações } \\
\mathbf{( t )}\end{array}$ & $\begin{array}{c}\text { Consumo } \\
\text { Aparente (t) }\end{array}$ & $\begin{array}{c}\text { População } \\
\text { (milhoses de } \\
\text { habitantes) }\end{array}$ & $\begin{array}{c}\text { Consumo } \\
\text { Aparente } \\
\text { (kg/hab./ano) }\end{array}$ \\
\hline 2000 & $843.376,5$ & $194.499,44$ & 57.001 & 980.874 & 169,799 & 5,78 \\
\hline 2003 & 990.272 & 152.514 & 113.722 & 1.029 .064 & 178,741 & 5,76 \\
\hline 2006 & 1.050 .808 & 180.374 & 77.139 & 1.154 .043 & 185,564 & 6,22 \\
\hline 2009 & 1.240 .813 & 230.173 & 300.800 & 1.170 .186 & 191,481 & 6,11 \\
\hline
\end{tabular}

Fontes: MPA (2012), IBGE (2011)

duas as principais fontes de informação para tentar se aproximar do consumo de pescado: o cálculo do consumo aparente do pescado e os dados oriundos das Pesquisas de Orçamento Familiar - POF.

O consumo aparente é um cálculo dado pela soma da produção pesqueira do país, mais as importações de pescado, menos as exportações. Por fim, divide-se esse montante pelo número total da população brasileira. A Tabela 2 apresenta estes dados para alguns anos selecionados na década de 2000. Pode-se perceber que, de acordo com o quadro de consumo aparente, obteve-se um crescimento significativo do ano de 2003 ao ano de 2006, sendo 2006 o ano de maior consumo aparente entre os demais citados. $\mathrm{O}$ ano de 2006 apresenta uma alta produção de pescado no país e uma baixa exportação em comparação a 2003. Já no ano de 2009, a produção de pescado é maior que a de 2006, porém a exportação é quase quatro vezes maior que 2006, onde obtivemos o resultado do consumo aparente de $6,11 \mathrm{Kg}$ por habitante. Sendo assim, o consumo aparente de pescado no Brasil sofreu um pequeno aumento ao longo da década e algumas oscilações, representadas graficamente na Figura 1.

As médias nacionais do consumo de pescado por habitante/ano, segundo as POF's (Pesquisas de Orçamento Familiar do IBGE) - Figura 2, situaram-se em 3,55kg nos anos 1986-1988, 3,02kg nos anos de $1995-1996$ e 4,57kg nos anos 2002-2003. Na pesquisa divulgada com os dados referentes aos anos de 2008/2009, o consumo médio auferido de pescado no Brasil corresponde a 4,032 kg/hab/ano, portanto abaixo do consumo aparente calculado tradicionalmente.

A partir dos resultados das POF's evidenciam-se também as diferenças regionais do consumo do pescado. Como exemplo dessas peculiaridades a região norte do Brasil apresentou um consumo médio de $17,544 \mathrm{~kg} / \mathrm{hab} / \mathrm{ano}$ em 2008/2009, o nordeste do país 4,965 kg/hab/anos, o sudeste 2,064 kg/hab/ano,

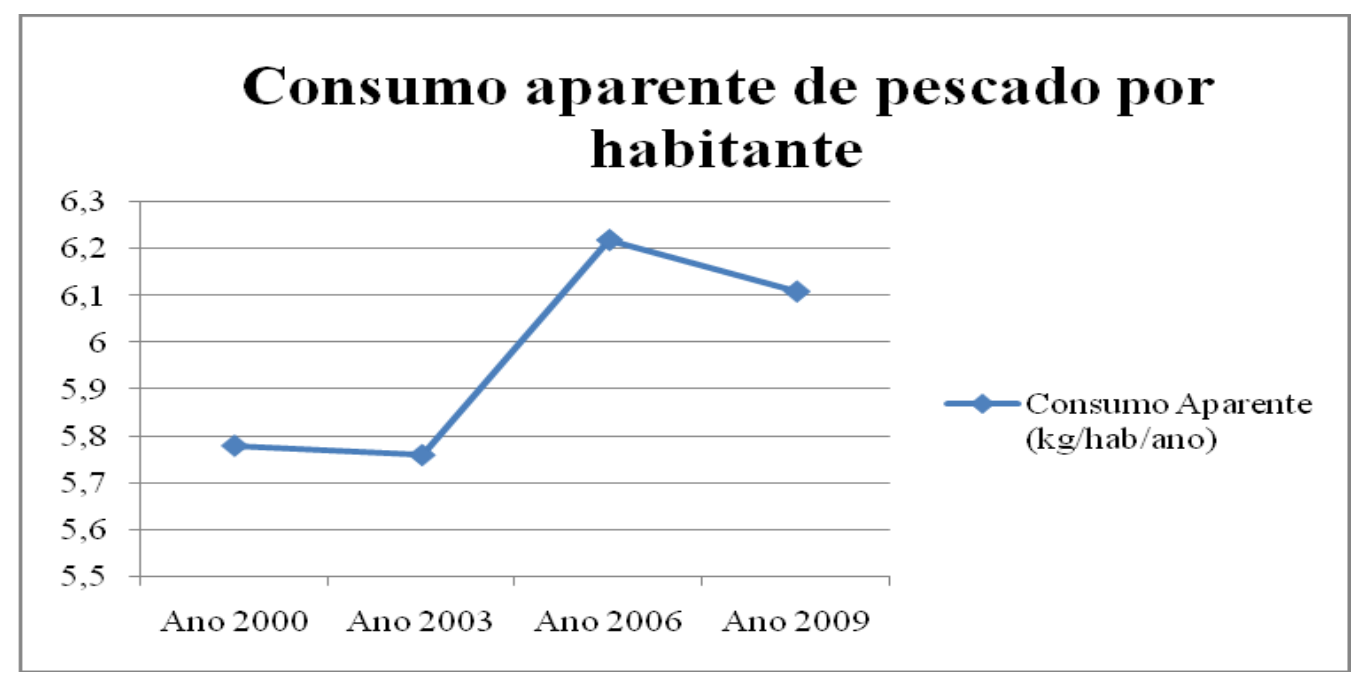

Figura 1: Brasil - Consumo Aparente de Pescado por Habitante

Fontes: MPA (2012), IBGE (2011) 


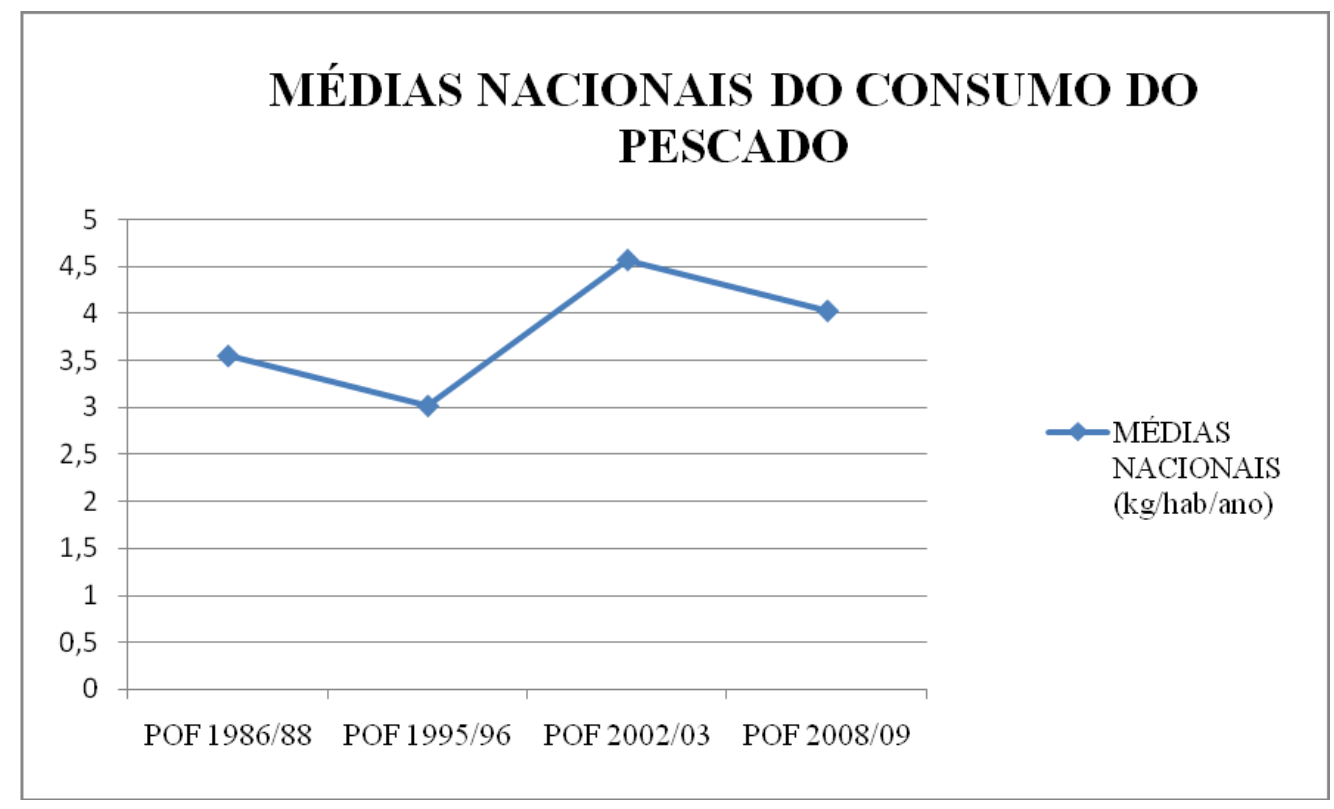

Figura 2: Brasil - Consumo médio do pescado

Fonte: POF/IBGE (2011)

no centro-oeste brasileiro o consumo é de 1,619 kg/ hab/ano e a região sul do Brasil apresenta o menor consumo de pescado dentre as regiões do país, com 1,597kg/hab/ano. Percebe-se uma grande diferença existente entre o norte do país e as demais regiões, fazendo com que os dados do consumo de peixe no Brasil elevem-se devido ao alto consumo da região norte do Brasil.

Tomando tais informações como balizadoras da pesquisa, buscou-se estabelecer algumas estimativas de comercialização. Pelas estimativas anteriores, o consumo de pescado em Santa Maria estava próximo ao indicado pelas POF's para o Rio Grande do Sul e para a Região Metropolitana de Porto Alegre, situada entre 1 e 1,5 kg/hab/ano. Com as informações obtidas pelos mesmos agentes de comercialização que foram indagados no ano de 2005, podemos inferir que esta ordem de grandeza permanece. Entretanto, a ausência de retorno de alguns estabelecimentos diante do pedido de informações não permite estabelecer as estimativas mais gerais.

Com relação à oferta de pescado, encontramos os produtos básicos, como o peixe fresco ou congelado, inteiro ou eviscerado, cortados em postas ou filetados. Além da diversidade de tamanhos, cortes e apresentação do peixe e outros pescados, tais como camarões, siris e moluscos. Uma diferença significativa entre as duas pesquisas refere-se à disposição dos filés de peixe mais populares. No levantamento realizado em 2005, predominavam as caixetas, com os filés congelados em conjunto, substituídos pelas bandejas com congelamento individual, onde o consumidor enxerga o produto

Nas visitas feitas aos pontos de venda do pescado, pode-se também observar a diversificação com relação aos produtos já processados, tais como barrinhas de merluza empanada, iscas de tilápia empanadas, bolinho de camarão, bolinho de bacalhau, bolo de peixe, lasanha de salmão, lasanha de camarão, escondidinho de camarão, entre outros. A venda destes produtos é viável pelo seu preparo prático, porém tais iniciativas são provenientes das indústrias alimentícias que trabalham em grande escala. Apenas uma das marcas é oriunda de uma cooperativa de produtores.

Os gostos da população estão fortemente influenciados por hábitos alimentares tradicionais. De acordo com a FAO (1997), "às vezes o aumento da demanda se deve por ocasião de feriados, festividades religiosas ou porque outro pescado ou outro tipo de alimento não está disponível". No caso de Santa Maria, a venda cresce significativamente na Semana Santa, nos distintos estabelecimentos que estimam um aumento de 4 vezes no período.

É quando os piscicultores da região direcionam sua produção para as vendas durante a Feira do Peixe Vivo. De forma geral, apenas alguns produtores locais sustentam um fornecimento contínuo de pescado ao longo do restante do ano, fato que motivou o incremento da oferta em algumas ocasiões, com o chamado "Caminhão do Peixe", passando pelos bairros e vendendo o produto fresco, durante algumas poucas semanas. 


\section{Considerações}

No município, o comércio varejista de pescado realiza-se, principalmente, nos mercados, supermercados, hipermercados, peixarias e em feiras. Em termos de fornecimento para restaurantes e refeitórios institucionais, as compras se realizam com agentes comerciais específicos, de acordo com cada estabelecimento.

Com o fim da pesquisa podemos estabelecer uma análise temporal do comércio de pescado na cidade de Santa Maria, podendo assim verificar a dinâmica ocorrida durante os seis anos passados do trabalho realizado em 2005 , obtendo informações que podem auxiliar no entendimento das transformações que ocorrem nesse setor.

Os objetivos propostos pela pesquisa, quais sejam: atualizar a estrutura do comércio varejista de pescado de Santa Maria e identificar parte dos circuitos de produção e consumo de pescado no município, puderam ser atingidos, evidenciando um setor dinâmico, com entrada e saída de novos agentes e produtos.

Tanto nesse estudo, quanto na pesquisa realizada em 2005, pode-se constatar que Santa Maria tem um significativo consumo de peixe, porém é bem abaixo do que o recomendado pelos organismos internacionais, ainda que a oferta de pescado no município seja variada, proveniente de circuitos locais, regionais, nacionais e internacionais de produção.

\section{Referências}

CARDOSO, Eduardo Schiavone et all. Os circuitos econômicos do pescado em Santa Maria, Geografia, Londrina: UEL, n.2, pág. 81-94, 2006.

DALL'ACQUA, Clarisse Torres Borges.

Competitividade e Participação: Cadeias

Produtivas e a Definição dos Espaços

Geoeconômico, Global e Local. São Paulo:

Annablume, 2003.

FAO (Organización de las Naciones Unidas para la Agricultura y la Alimentación). Manual para la comercializacion de los produtos de la acuicultura. Valparaíso: FAO, 1997.

FAO (Organización de las Naciones Unidas para la Agricultura y la Alimentación). El Estado Mundial de la Pesca y la Acuicultura. Roma: FAO, 2009.
IBGE (Instituto Brasileiro de Geografia e Estatística). Pesquisa de Orçamentos Familiares. Disponível em <http://www.ibge.gov.br>, acessado em 27 de novembro de 2011.

IBGE (Instituto Brasileiro de Geografia e Estatística). Estatísticas. Disponível em <http:// www.ibge.gov.br $>$, acessado em 2 de outubro de 2011.

MPA - Ministério da Pesca e Aquicultura. Boletim Estatístico da Pesca e Aqüicultura - Brasil 2010. Brasília: MPA, 2012.

PAULILLO, Luis Fernando. Redes de Poder e Territórios Produtivos. São Carlos: RIMA/Ed. da UFSCAR, 2000.

SANTOS, Milton. Metamorfose do Espaço Habitado. São Paulo: Hucitec,1997

SORJ, Bernardo. O Consumo do Pescado no Brasil. In CIRM. Pesca no Brasil. Brasilia: CIRM, 1986. 